\title{
A Time May Soon Be At Hand
}

\author{
Saqib Masroor ${ }^{1}$ and Donlad Glower ${ }^{2}$ \\ ${ }^{1}$ University of Toledo Medical Center \\ ${ }^{2}$ Duke University Medical Center
}

September 10, 2020

Title: The Time May Soon Be At Hand

Running Head: Time May Soon Be At Hand

Authors: Saqib Masroor, $\mathrm{MD}^{1}$ and Donald B. Glower $\mathrm{MD}^{2}$

1. University of Toledo College of Medicine and Life Sciences, Department of Surgery, Division of Cardiothoracic Surgery

2. Duke University Medical Center, Department of Surgery, Division of Cardiothoracic Surgery

Meeting Presentation: None

Disclosure: None

Word Count: 1213

Corresponding Author:

Saqib Masroor, MD, MHS

Chief, Division of Cardiothoracic Surgery

University of Toledo College of Medicine and Life Sciences

3000 Arlington Avenue, Toledo, Ohio 43614

Phone: 419-383-5150

Fax: 419-383-3149

Surgeons have usually associated left atrial appendectomy (or exclusion) as a part of the Maze procedure or some iteration thereof. However the strategy of left atrial appendectomy to prevent embolism in patient with rheumatic heart disease and atrial fibrillation was first implemented by Madden in 1949, long before the Maze procedure was developed (1). Not soon thereafter it was also shown that ligation of LAA can still lead to embolism (2), thereby demonstrating that in order to prevent embolism in patients with AF undergoing LAA excision/exclusion, the surgical technique is also important. Years later, in his report of 306 patients (3) who underwent maze procedure and followed for up to 11.5 years, Dr Cox reported two early strokes with an incidence of $0.7 \%$ and only one more stroke in the follow-up period. This benefit was ascribed to the maze procedure restoring sinus rhythm and atrial transport, and secondarily to obliteration of the LAA. Since that time, many studies have reported on the success of the maze procedure in restoring sinus rhythm as well reducing the incidence of stroke in patients with AF (4-5). 
However, two questions remain. First, is the stroke reduction by maze procedure due to restoration of rhythm or due to obliteration of the LAA? Second, is the surgical technique important in successful obliteration of LAA?

In this issue of the Journal of Cardiac Surgery, Jiang et al (6), report on 860 patients undergoing mitral valve replacement, who were randomized to LAA exclusion $(\mathrm{n}=521)$ vs no exclusion $(\mathrm{n}=339)$. The primary endpoint was perioperative stroke within 30 days of surgery. This was a relatively younger population with a mean age of 53 years including $68 \%$ with rheumatic disease. Not unexpectedly, almost $20 \%$ of these patients had a mural thrombus in the LAA. None of the patients underwent surgical ablation for AF. Most patients underwent concomitant valve or coronary artery bypass grafting. The exclusion group had significantly reduced incidence of stroke at $0.6 \%$ vs no-exclusion group which had a stroke incidence of $2.7 \%$ $(\mathrm{p}<0.05)$. However further subgroup analysis revealed that this benefit was limited to the patients who had pre-operative AF. In these patients with pre-existing $\mathrm{AF}(\mathrm{n}=543), 373$ underwent exclusion and 170 did not. The incidence of stroke in the exclusion group was $1 / 14^{\text {th }}$ that in the no-exclusion group $(0.3 \%$ vs $4.5 \%)$. In patients without pre-existing $\mathrm{AF}(\mathrm{n}=323)$, no statistically significant benefit of LAA exclusion was seen in the reducing the risk of perioperative stroke, even though $17.6 \%$ of these patients did develop postoperative AF.

This is the first randomized study to demonstrate the benefit of LAA exclusion, without rhythm restoration, in reducing perioperative stroke in patients with $\mathrm{AF}$ undergoing mitral valve replacement. The benefit appears to be similar in magnitude to the historical control reported by Dr Cox (3). None of the patients received any ablation as the maze procedure. This study also demonstrates the importance of the surgical technique in LAA exclusion. The authors focus on two principles of LAA closure. The first is reducing the tension at the suture line of the LAA orifice, by what can be described as a plicating stitch, which pulls the left atrial tissue up towards the posterior mitral annulus, thereby reducing the tension at the orifice of the LAA. Secondly, the two-layer closure - a horizontal mattress suture followed by the running over-sewing layer of monofilament suture - makes for a durable closure of LAA, as demonstrated by their excellent outcomes.

However, there are many shortcomings of this study. This is a relatively short study with only perioperative outcomes at 30 days after surgery. Longer term follow-up would have been better. Secondly, even though the groups were randomized, there are many differences in the two groups, including the gender distribution, incidence of hypertension, LV dysfunction, pre-existing AF, presence of mural thrombus, concomitant tricuspid valve surgery; all of which had a higher proportion of patients in the exclusion group as compared to the no-exclusion group. In order to balance the confounding variables between the two groups, it would have been better if the authors had used a propensity score matching strategy.

In addition to 3 randomized trials already in the literature (7-9) and the study of Jiang et al. (6), there are 2 ongoing randomized trials examining LAA exclusion. These include the Left Atrial Appendage Occlusion Study (LAAOS) III trial in 4700 patients with AF undergoing cardiac surgery (10) and the AtriClip Left Atrial Appendage Exclusion Concomitant to Structural Heart Procedures (ATLAS) trial in 2000 patients without AF but at high risk to develop postoperative AF (ClinicalTrials.gov Identifier: NCT02701062).

At present, surgical exclusion of the LAA has only a Class IIb indication for patients with AF undergoing cardiothoracic surgery by ESC (11) and ACC/AHA (12) guidelines. However, within the next 2 years we may have 6 randomized trials likely to warrant changes in the national and international practice guidelines. That time may soon be at hand!

\section{References}

1. Madden JL. Resection of the left auricular appendix. J Am Med Assoc 1949;140(9):769-72

2. Leonard FC and Cogan MA. Failure of ligation of the left auricular appendage in the prevention of recurrent embolism. N Engl J Med 1952;246(19):733-5

3. Cox JL, Ad N and Palazzo T. Impact of the maze procedure on the stroke rate in patients with atrial fibrillation. J Thorac Cardiovasc Surg 1999;118:833-40 
4. Kim JB, Yun TJ, Chung CH, et al. Long term outcome of modified maze procedure combine with mitral valve surgery: Analysis of outcomes according to type of mitral valve surgery. J Thorac Cardiovasc Surg 2010;139:111-7

5. Bando K, Kasegawa H, Okada Y, et al. Impact of preoperative and postoperative atrial fibrillation on outcome after mitral valvuloplasty for nonischemic mitral regurgitation. J Thorac Cardiovasc Surg 2005; 129:1032-40

6. Jiang $\mathrm{S}$, Zhang $\mathrm{H}$, Wei $\mathrm{S}$, et al. Left atrial appendage exclusion is effective in reducing postoperative stroke after mitral valve replacement. J Card Surg

7. Whitlock RP, Vincent J, Blackall MH, Hirsh J, Fremes S, Novick R, et al. Left atrial appendage occlusion study II (LAAOS II). Can J Cardiol. 2013;1443-7.

8. Nagpal AD, Torracca L, Fumero A, Denti P, Cioni M, Alfieri O. Concurrent prophylactic left atrial appendage exclusion: results from a randomized controlled trial pilot study. Eur J Cardiothorac Surg. 2009;36:553-7.

9. Healey JS, Crystal E, Lamy A, Teoh K, Semelhago L, Hohnloser SH, et al. Left Atrial Appendage Occlusion Study (LAAOS): results of a randomized controlled pilot study of left atrial appendage occlusion during coronary bypass surgery in patients at risk for stroke. Am Heart J. 2005;150:288-93.

10. Whitlock R, Healey J, Vincent J, Brady K, Teoh K, Royse A, et al. Rationale and design of the left atrial appendage occlusion study (LAAOS) III. Ann Cardiothorac Surg. 2014;3:45-54.

11. Kirchhof P, Benussi S, Kotecha D, Ahlsson A, Atar D, Casadei B, et al.; ESC Scientific Document Group. 2016 ESC Guidelines for the management of atrial fibrillation developed in collaboration with EACTS. Eur Heart J. 2016 ;37:2893-2962.

12. January CT, Wann LS, Alpert JS, Calkins H, Cigarroa JE, Cleveland JC Jr, et al.; ACC/AHA Task Force Members. 2014 AHA/ACC/HRS guideline for the management of patients with atrial fibrillation: executive summary: a report of the American College of Cardiology/American Heart Association Task Force on practice guidelines and the Heart Rhythm Society. Circulation. 2014;130:2071-104. 